\title{
ELABORATION OF THE SUSTAINABLE UNIVERSITY MODEL AND ITS APPLICATION IN THE HIGHER EDUCATION SYSTEM OF THE REPUBLIC OF MOLDOVA
}

\section{Alina Suslenco ${ }^{1}$}

DOI: https://doi.org/10.30525/978-9934-26-049-0-11

Abstract. This paper represents a well-founded scientific approach, which elucidates the need to develop a model for ensuring the sustainability in higher education institutions. The aim of the paper is to develop its own model of sustainable development of universities in the Republic of Moldova in order to increase their competitiveness. The research problem is to find an optimal model with the purpose of ensuring a sustainable development of universities in the Republic of Moldova. The research question: what model of sustainable development can be applied to higher education institutions in the Republic of Moldova. Therefore, in this context, several models of the sustainable development of higher education institutions were reviewed, and towards the end, the own model of ensuring sustainability within the universities of the Republic of Moldova was developed. The model includes an innovative approach on the creation of a sustainable university in the conditions of the Republic of Moldova. The model proposed by us is based on ensuring a balanced development from an ecological-economic-social point of view, along with the most important levels that must be developed within a university in order to ensure a sustainable development. The research methodology focused on the use of a range of relevant methods such as: analysis, synthesis, induction, deduction, abduction, documentation, scientific abstraction, which helped us to advance in research and obtain the expected results. In conclusion, we can reiterate that each university, which claims to step firmly on the path of competitiveness and is able to raise students' interest, motivate their development, create notoriety among stakeholders, has to develop a model of sustainable, viable, competitive development that could ensure a secure path in the future. The model proposed by us is a viable one, and deserves

\footnotetext{
${ }^{1} \mathrm{PhD}$, University Lecturer,

Alecu Russo Balti State University, Republic of Moldova

(C) Alina Suslenco
} 
to be applied in the context of increasing competitive pressures. This model will help the universities to deal with competition, to overcome the problems and challenges faced by higher education institutions in the Republic of Moldova, such as the decrease of college enrolment rate and the number of students, the diminution of notoriety, lack of viable tools applied within the university in the interest of ensuring competitive advantages. Applying our own model constitutes an innovative approach for strengthening the sustainability in higher education institutions based on effective tools that will definitely contribute to increasing the performance and ensuring sustainability in higher education institutions in the Republic of Moldova.

\section{Introduction}

Universities, as agents of change, as centres of culture, where specific human values, skills and abilities dominate and are shaped, have to fulfil the utmost mission to implement the culture of sustainability in their activity. This must be reflected by means of courses and scientific research focused on sustainability issues, intended for students, as agents of change.

The concerns of the universities regarding the achievement of sustainability must become systematic and important institutional matters, as steps towards strategic development on the path to competitiveness.

In pursuance of creating a sustainable university, it is necessary to reorganize the education system, as well as to insert the objectives related to sustainable development in the university daily activities. This can be achieved through the integration of sustainability in the fields of research, education that will focus on sustainability-related training skills, helping students be more competitive on the job market and have successful careers.

Just as a sustainable university is the university that harmoniously combines education, research through a complex process of ensuring an interdisciplinary balance in the context of optimal use of the natural environment, ensuring social equity and economic well-being by collaborating with stakeholders involved in this process, the education system in the Republic of Moldova must switch its direction towards transforming universities into sustainable higher education institutions that manifest a successful activity by forming generations of young specialists capable of manifesting responsible activities and becoming vectors of change towards building a sustainable society. 
In this context, we decided to carry out this scientific endeavour, through which to highlight the best way to achieve sustainability in higher education institutions in the Republic of Moldova.

\section{Theoretical aspects regarding ensuring sustainability in the university environment}

Sustainability is a concept focused on achieving human development goals, and, simultaneously, supporting the capacity of the ecosystems by providing natural resources and protecting life and nature, without diminishing the chances of future generations.

This concept is perceived as significant in ensuring social and economic development, as it was first defined by the World Commission on Environment and Development (WCED) of the United Nations Organisation in 1987 [12].

The report „Our Common Future" defined sustainability as "the development that meets the needs of the present without compromising the ability of future generations to meet their own needs" [12], being conceptualized within the framework of environmental limitations and the human needs.

WCED sought to explore the causes of the environmental degradation, as well as the interconnections between social equity and economic growth. Sustainability objectives integrate the three economic, social and environmental aspects for ensuring the development of future generations. Given the current activities at the international level, the United Nations Agenda for Sustainability, based on the document "Transforming our World: The 2030 Agenda for Sustainable Development" was drafted in 2015. The new Sustainability Objectives, from the perspective of 2030, underline, among others, the relevance of higher education in the efforts for a better future [4].

The inclusion of the UN sustainability objectives in the curriculum will support the development of the future-oriented skills. This can be achieved by promoting social, economic and political change, which can be reinforced by professional leaders and specialists.

Recent developments also show that the European Union Strategy "Europe 2020: a strategy for smart, sustainable and inclusive growth" adopted in 2010 highlights, in this context, the crucial importance of innovation, education, digital society, training and lifelong learning [18]. 
According to the Global Action Program on Education for Sustainable Development, adopted by UNESCO in 2014, we can highlight the fact that political agreements, financial incentives and modern technologies are not enough to achieve sustainability [11].

A sustainable university is that university which harmoniously combines education and research through a complex process of ensuring an interdisciplinary balance, in the context of optimal use of the natural, social and economic environment by collaborating with stakeholders involved in this process.

According to the definition offered by Velazquez, a sustainable university always refers to the environmental, economic and social concerns it should have, regarding its activity and responsibility to "lead by example". The researcher states that a higher educational institution university "involves and promotes, on a regional or a global level, the minimization of negative environmental, economic, societal, and health effects generated in the use of their resources" [22, p. 812].

Another researcher, Cole, mentions that "a sustainable campus community acts upon its local and global responsibilities to protect and enhance the health and well-being of humans and ecosystems [...] to address the ecological and social challenges" [3, p. 30].

On the other hand, the renowned researchers Alshuwaikhat and Abubakar, elucidate that "a sustainable university campus should be a healthy campus environment, with a prosperous economy through energy and resource conservation, waste reduction and an efficient environmental management, and promotes equity and social justice" [1, p. 1778].

From the theoretical approaches presented, we observe the urgent need to ensure a sustainable, balanced development of higher education institutions in order to ensure a synergy of sustainable development of the whole society.

\section{Possibilities for assessing the sustainability in higher education institutions}

Achieving sustainability in the academic environment can be assessed through a number of specific indicators. The most complete and comprehensive list of indicators is given by the rating UI Green Metric World Ranking, a program developed by the University of Indonesia, used 
to assess the implementation of sustainability programs and the state of university campuses [24]. The list of indicators provided by the University of Indonesia is a complex one [6, p. 18].

Based on the data, we notice that the list includes 6 groups of criteria according to which the evaluation of the university sustainability is performed:

1. Environment and infrastructure - this category includes several aspects, such as: the ratio of the open space area to the total area, the ratio of the area to the number of people, location, availability of a welldeveloped and ecological transport, campus areas covered with trees and shrubs, campus areas covered with lawns and flower areas, the availability of recreational areas, materials, resources, equipment, the environmental protection and the possibility of recovering the constructions and surfaces, the comfort of the living environment. Evaluating each of these criteria, one tries to identify the efforts of the universities in achieving the university sustainability.

2. Energy efficiency and climate change - this category of indicators includes: the use of energy-intensive appliances, the implementation of smart construction programs, the renewable energy policy, the ratio of the electricity consumption to the population on campus, energy saving programs, the implementation of green building elements, the policy of gas emission reduction, climate change adaptation and mitigation program, the ratio of the total university carbon emission to the total open area of the campus, the greenhouse gas emission reduction program. Each of these indicators helps the universities assess the energy efficiency and the consideration towards climate change. Obviously, in order to have good results in this category of indicators, it is necessary for the university to focus its attention on environmental issues and to show concern for energy issues, thus including these issues in the university strategy;

3. Waste - this category includes several indicators, such as: university waste recycling program, recycling of toxic waste, recycling of organic waste, recycling of inorganic waste, the sewage system, the policy to reduce the use of paper and plastic on campus, hazardous waste and materials, waste collection and disposal, protection against rodents and insects, sanitation of public areas. The issue of waste recycling is a major concern for developed countries and the universities in these countries, as agents of change, they focus their attention on solving these major problems; 
4. Water - this category includes several indicators, such as: water conservation program, water recycling program, industrial water consumption. The issue of water is a global issue, and, in this context, one of the principles of sustainability set out in the 2030 Agenda is the access to safe drinking water for all countries. In this context, universities must also focus on ensuring rational water consumption on university campuses;

5. Transport - this category consists of the following evaluation indicators: the ratio of transport (cars and motorcycles) to the population on campus, the ratio of university bicycles to the total number of means of transportation used, the policy of limiting the number of cars on campus, the policy of restricting parking on campus, the university bus service, the cycling and walking policy. In order to limit the $\mathrm{CO}_{2}$ gas elimination and the manifestation of a healthy environment for everybody, universities must also be concerned with limiting the air-polluting transport such as cars, buses, in exchange for a healthy mode of transportation, such as bicycles. The largest universities in the world have already installed parking spaces for bicycles, but also for renting bicycles in order to promote a healthy environment for everybody;

6. Education and management - this category consists of the following indicators such as: the ratio of the number of courses related to ecology to the total number of courses taught, the ratio of the funding allocated to sustainability to the total amount funded by the higher education, publications on sustainability, measures to ensure sustainability, student organizations dedicated to sustainability, websites for sustainability, innovation, research and development, implementation of an environmental management system. Analysing this category of indicators, we can observe the fact that in order to be sustainable a university must target its academic, research and managerial efforts on the issues of achieving sustainability [6, pp. 18-21].

Thus, a sustainable university must pay attention to the courses taught, including topics related to sustainability within the range of course topics. Obviously, this fact encourages the universities to show a greater interest in the issues related to sustainability and, consequently, to come up with solutions to achieve a high level of sustainability.

In addition, universities must show a keen interest in providing financial resources to address infrastructure and environmental issues, energy efficiency and climate change, waste, water, transportation. Therefore, 
universities need to allocate financial resources, either from internal sources, or from accessing national or international projects that could help the university to address these issues.

Another direction followed by the universities consists in the attention given to research and innovation, which must be closely linked to sustainability. In developed countries, universities focus on researching environmental issues, finding solutions to improve and solve them through research activities, collaboration with national and international organizations, but also through innovation and technology transfer activities based on laboratories and research centres.

A sustainable university must also show an increased interest in creating a website that will address issues of sustainability, the involvement of students in activities dedicated to achieving sustainability issues. Thus, students represent the engine of change within a sustainable university, showing interest and motivation in solving problems related to achieving sustainability.

\section{The teacher-student relationship in the sustainable university}

In order to achieve sustainability and integrate sustainability issues into the activities of the universities, it is necessary to ensure the reorientation of the existing education system in the interest of sustainability, which is possible by means of providing teacher training on the issue of achieving sustainability, by forming a sustainable university, and by discussing several approaches that would allow the integration of education ideas and methods for sustainability in the educational process.

The result of sustainability should be a review of the teaching material by the teacher in order to cultivate sustainability education within the taught subjects. One of the preconditions for an effective implementation of sustainability in the learning process is the student-cantered approach.

In this approach, the role of the teacher is to create the necessary conditions (educational environment) for personality development, namely:

- providing advice and assistance related to sustainability issues;

- applying a democratic and a respectful communication style;

- stimulating the motivation in order to acquire the knowledge and skills in the direction of sustainability;

- involvement in the learning process of each student, taking into account his/her abilities and character traits. 
The student gradually becomes the main actor in the educational process, and the main goal is to develop his/her skills in the direction of sustainability.

Sustainability education is much broader than environmental education because it includes a significant proportion of social and economic issues. It must be acknowledged that in modern environmental education, the essential causes of the environmental problems are not sufficiently analysed, as the main focus is placed on eradicating the "symptoms" of these problems. Summarizing some results, we can conclude that the key objective of sustainability education is the formation of a personality with a systemic, critical, socially and ecologically oriented vision and an active civil position.

Sustainability education should use all the possibilities of modern teaching technologies, media and multimedia in combination with the traditions, culture of people and the experience of previous generations.

The most important goals of education for sustainability are:

- developing a systemic vision and critical thinking;

- acquiring new knowledge and skills that contribute to achieving the sustainability of society;

- teaching the need to ensure a healthy lifestyle;

- the formation of moral values in the context of achieving sustainability;

- training in sustainable consumption.

In order to accomplish the established tasks, it is obviously necessary to seriously change the approaches to organizing the traditional learning process. What is certain is that the individual stages and elements of education for sustainability will have to be implemented in other structures, such as various public institutions, local community, family, as well as bodies of the national economy.

Therefore, it is necessary to learn how to organize this component of the lifelong learning process, so that the student can apply and supplement the knowledge and skills acquired in the classroom or in practice, in everyday life.

Under no circumstances should student's communication with a teacher be replaced by working with electronic or printed educational materials. New information technologies, computers, video and audio equipment can and must complement and help the active interaction of teachers and students. 
The importance and role of teachers is increasing. At the same time, as we have already mentioned, the role of the teacher and the learning objectives change significantly. The time has come when it is necessary to organically introduce the concept of sustainable lifestyle in different course units.

It is important to teach students to analyse actions from the point of view of sustainability, to assess the consequences, to predict the situation.

In the modern sense, the learning process is considered a process of interaction between a teacher and the students for the sake of students' familiarization with certain knowledge, skills, and values. Three main forms of interaction between teachers and students have developed, established and extended.

The first category of methods is represented by the "passive teaching methods", showed in Figure 1. It is a form of interaction between students and teachers, in which the teacher is the main actor and controls the progress of the lesson, and the students act as passive listeners, following teacher's instructions. The teacher's interaction with the students throughout the passive lessons is made through surveys, independent work, assessment, tests, etc. [2].

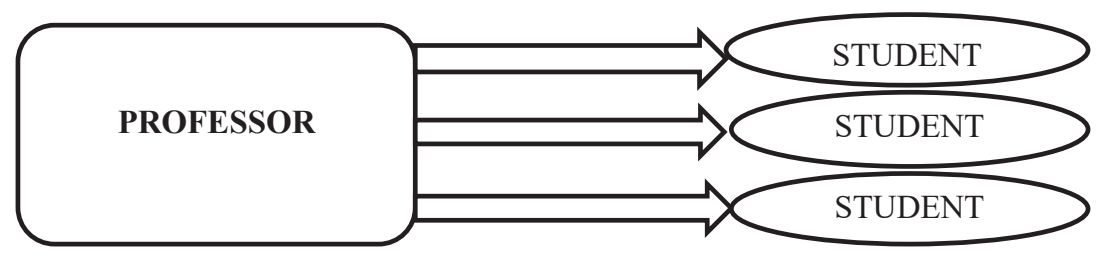

Figure 1. Passive Teaching Methods

Source: adapted by Azizov A., 2009

From the point of view of modern teaching methods and the efficiency of assimilation of educational material by students, the passive method is considered the most inefficient, but, despite this, it also has some advantages.

This is a relatively easy preparation for the lesson by the teacher and the possibility to present a relatively large amount of teaching materials in the limited time frame of the lesson. Given these benefits, many teachers prefer the passive method over others. 
We can mention that, in some cases, this approach works successfully in the hands of an experienced teacher, especially if the students have clear objectives that aim at an in-depth study of the subject.

The lecture is the most common type of passive lesson. This type of lesson is widespread in the universities, where adults study, fully accomplished people, motivated to study deeply the given subject.

Another category of approaches is represented by the "active methods", which is shown in Figure 2. This is a form of interaction between students and teachers, in which the teacher and the students interact with each other during the lesson. The students are not passive listeners here, but they are active participants in the lesson (Azizov, 2009).

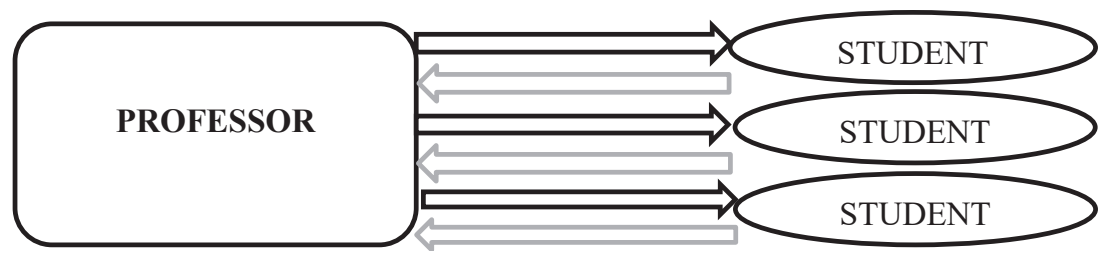

Figure 2. Active Teaching Methods

Source: adapted by Azizov A., 2009

If, in a passive lesson, the main actor and the lesson manager is represented by the teacher, at this point, the teacher and the students are on equal terms. If the passive methods imply an authoritarian style of interaction, then the active methods postulate a more democratic style. Frequently, an equal importance is given to both, active and interactive teaching methods, however, despite this generalisation, they have significant differences.

Another category of teaching methods is described by the "interactive methods", which are schematically shown in Figure 3. The word "interactive" comes from English ("inter" stands for reciprocal, "act" means to act), which, generally, denotes the action of interaction, the state of being involved in a conversation, a dialogue with someone. In other words, unlike active methods, the interactive ones are focused on a wider interaction of students, not only with the teacher, but also with others, and on the dominance of students' activity in the learning process. The 
teacher's role in the interactive lessons is reduced to the organization and direction of students' activities to achieve the objectives of the lesson. Students actively explore the material through interactive exercises and tasks (Azizov, 2009).

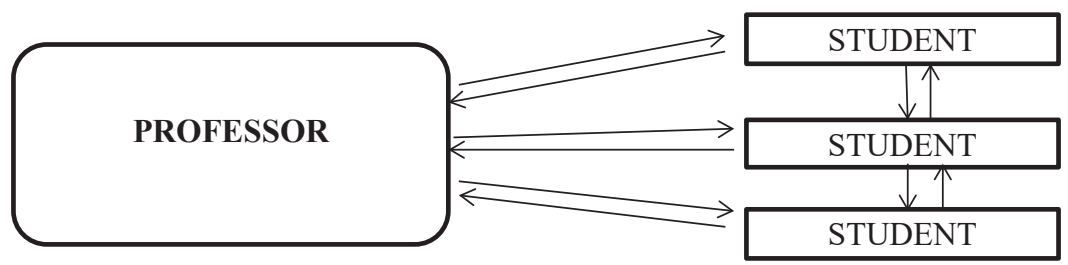

Figure 3. Interactive Teaching Methods

Source: adapted by Azizov A., 2009

An important difference between the interactive and regular exercises is that, by fulfilling them, students not only consolidate the material already studied, but learn a new one.

Kindness and mutual support in the classroom enable the effective achievement of education for sustainability. Also, students accumulate new knowledge and develop cognitive activities, improve the level of cooperation between them.

Interactive methods exclude the dominance of one speaker over others and, consequently, of an opinion over others. The form of interactive learning develops critical thinking, independence, contributes to the analysis of situations and circumstances, promotes the development of the ability to make deliberate decisions, allows to gain experience of participation in discussions and communication with other people.

This approach can develop an ambitious vision of what a sustainable ideal university would look like once it reaches the "stabilization" stage, but there is a risk of minimizing the significant dynamics in the real world. For example, assuming that an ideal and stabilized state can actually be achieved, could be quite discouraging for potential change agents, whose universities are far from "ideal" in a number of areas. The analysis of best practices sometimes omits how these practices were developed and how these practices can have an impact in different contexts and cultures, and can in fact be considered "best" practices. 


\section{Models of ensuring sustainability in higher education institutions}

A very complex model of a sustainable University was developed by Velazquez et al. [22, pp. 814-818]. Their model aims to provide a clear perspective on what responsible people should do in their sustainability initiatives to transform their university into a sustainable one. The model was created by using a process of evaluating and measuring the best practices used within the universities, in order to promote a sustainable development in eighty higher education institutions around the world.

In our opinion, this model can be improved with recommendations on how to transform the university into a sustainable one. To complete the model of Velazquez et al., we developed our own model, where the principles for the process of integrative development in the direction of sustainability were used (Figure 4).

The university, like any other organization, consumes natural resources, produces waste and affects the environment, employs people to provide educational services to the community, thus contributing to the economic development. As identified by Velazquez et al., after consulting eighty higher education institutions and the literature, the university should address the following environmental issues such as: energy efficiency, equity and poverty, water efficiency, access for people with disabilities to the university campus, social transport, including student transport and personnel, waste management, natural heritage, nutrition services, health and safety, ergonomics and environmental procurement [22, pp. 814-818].

The universities thinking about the future are already acting as agents in promoting the principles of sustainability in society, and will play an even more crucial role in the future. The knowledge, skills and values, which a university forms, transfers and promotes, would influence, and even shape the future society. The main means available for universities, in this regard, are the substantiation of basic knowledge, values and skills of students using 2 fundamental areas: education and research.

The whole education system will have to internalize the principles and objectives of sustainability as an integrator of the knowledge, skills and competences necessary for personal existence and performance in the modern world. Sustainability education can be a distinct study discipline, but, in line with the EU best practices, it should be embedded in all training programs designed and organized on areas or disciplinary modules present 
in the curriculum, in order to learn sustainable production and rational consumption in relation to resources, in acquiring the principles of cultural diversity, good governance and the rule of law [4].

Similarly, the educational approach to sustainability should also pay particular attention to its formal, informal and non-formal components.

The researcher Rhoten et al. suggest applying the "Interdisciplinary Education”, which is: ,a mode of curriculum design and instruction in which individual faculty or teams identify, evaluate, and integrate information, data, techniques, tools, perspectives, concepts, and or theories from two or more disciplines or bodies of knowledge to advance students' capacity to understand issues, address problems, appraise explanations, and create new approaches and solutions that extend beyond the scope of a single discipline or area of instruction" [13, p. 3].

The model we propose does not focus on teaching methods, but suggests that knowledge, values and skills can be provided to students through formal, non-formal and informal education. The model also recommends that research focus on the three pillars of sustainability: society, economy and environment, and presents some possible research topics for each of the three components.

Universities operate and manifest an impact on communities and ecosystems, ranging from local to global levels. Sustainability education requires cooperation and partnership between multiple stakeholders: central and local authorities, health education and science, the private sector, industry, transport and agriculture, trade unions, the media, NGOs, the local community, citizens and the international organizations.

Developing greater synergies between universities and the community in order to shape and achieve the goals of the sustainable approach should become a priority for sustainable universities.

It is important for universities to have knowledge of what to do in order to become sustainable universities, but it is essential to know what measures they need to take, in this regard. The proposed model does not intend to have a rigid and inflexible structure, because sustainability is a complex issue and is approached differently by different actors.

However, the model aims to be a guiding tool for exploring strategies for transforming the university into a sustainable one.

Velazquez et al pointed out that "implementing the sustainable university model is a process of continual improvement in environmental, 
social, and economic performance that should be made through incremental (an.)" [22, p. 818]. In this model, we suggested the steps to be taken by a university on its path to achieving sustainability.

In addition to the 5 principles of the Valanzquez model: leadership and vision, social networking, participation, education, learning and research integration, we have inserted another principle, which is performance management. These steps are illustrated in the model, in the shape of 6 arrows that form a closed loop.

The model proposed by us, suggests a sequence of 3 steps, inspired by the model offered by Velazquez et al:

1. Developing a vision of sustainability for the university - this is the first step in the strategic move towards a sustainable university. At the moment, there are no barriers or constraints besides imagination and creativity. When substantiating the vision, attention must be paid to motivating participants to take part in the process of transforming the university into a sustainable one.

2. Creating a mission in the context of achieving sustainability - an effective mission statement describes, in simple but powerful terms, the organization's fundamental, unique goal. The vision should be an important basis for the development of the mission. The mission statement tends to be more realistic than a vision. However, it is fundamental that when the sustainable university declaration is created, it must be included as one of the core values of the university.

3. Sustainability Committee at the university level - the organizational structure of a university that should reflect the commitment to sustainability by implementing the strategies needed to accomplish the mission.

The Committee should have representatives from all stakeholders, and its responsibilities should assist decision-makers in disseminating and receiving information, coordinating initiatives, raising funds, but also developing, promoting and monitoring the implementation of policies aimed at achieving sustainability within the university [22, pp. 814-818].

Social network includes all stakeholders, people affected by the process of achieving sustainability, as well as, all relevant stakeholders. Stakeholders are represented by human resources, regardless of whether they are potential/ current/ former employees of the educational institution, partners, competitors, consumers, etc. 
In order for a university to improve its sustainability prospects, it must create, develop and maintain open communication in relation to all the stakeholders. Networking between partners can streamline the activities of the educational institution.

The model presents three steps to be followed when creating the social network:

a. an information network simply aims to exchange information without pursuing a common goal of combining this information;

b. a network of knowledge aims to combine information and pursues a common goal. More trust in in using each other's knowledge is needed;

c. an innovation network pursues a common vision, requires great trust in each other and aims to offer innovative solutions to future challenges.

Participation focuses on how all people in the social network are involved in the process of transforming the university into a sustainable one. The researchers shaped the idea that meetings, where team members communicate openly on issues of sustainability interest, and participate in problem solving, give better results than those where members are sitting and listening. There are different levels of participation in meetings, but the most effective is the interactive treatment of sustainability issues.

According to Sterling, sustainable education means "both the grounding and possibility of a change of educational paradigm as a whole" $[17$, p. 49], while the shift to sustainability largely depends on the change in mentality, the difference in mentality that lies between a sustainable or a chaotic future.

As Schumacher observed the volume of education continues to rise, as does pollution, resource depletion and the dangers of an ecological catastrophe. Sustainable education should be a different education: an education that educates us in the depths of things [15, pp. 5-7].

Sustainability is not just a matter of adding new assignments to the overcrowded curriculum, underlines Sterling, but it is "the development of a collective intelligence and culture" in a university that "audits its curriculum in sustainability terms [...]; engages its students and their enthusiasms in real-life issues [...]; encourages and facilitates creative, critical and systemic thinking; experiments with inter- and transdisciplinarity; works with staff to develop varied and participative pedagogies; promotes an ethos of carrying and inclusion" [17, p. 59]. 
Paula Lindroos reiterates that learning about sustainability is guided by a principle of organizing science and, at the same time, focusing on students' problem-solving skills. This means that both content and learning methods become important for courses [10].

Tilbury affirms that „Environmental Education for Sustainability is an innovative and interdisciplinary process requiring participative and holistic approaches to the curriculum" [19, p. 98], and believes that innovation is needed to achieve a sustainable university.

Sterling strongly advocates for the transformation of education into "sustainable education" and supports the reorientation of educational policies, programs and practices using the synergy between ecological and systemic thinking [17, pp. 48-53]. Sterling also suggests that we must make an escape from the present into the future by applying modern teaching methods that practice sustainable education. He also argues that a sustainable educational culture must move away from current concerns, and focus on achieving sustainability.

\section{Own model of ensuring sustainability}

\section{in higher education institutions in the Republic of Moldova}

The conceptual model developed by us (see Figure 4) shows what many scholars have argued: sustainability education should be integrated into university practices, to overcome the barriers that arise in the process of reorienting teachers towards sustainable education: lack of awareness that reorientation to achieve sustainability is essential; lack of clarity that involves reorientation; discipline limits, boundaries that reward teachers for work in the limits of only one discipline, inadequate financial and general resources for support for change, and lack of support for innovative change.

Therefore, leadership engagement, social networking and participation should facilitate overcoming the barriers. Other tools, such as a website for disseminating information, best practices, problem-solving, mainly aimed at teaching in universities, but also involving students, could facilitate the emergence of sustainable education.

Research integration. Increasing the level of integration is currently an important policy objective for the European research. Integration offers the opportunity to find new solutions to existing and future challenges. Integration between subjects taught, research and practice, is increasingly a recognized prerequisite for addressing complex issues more efficiently. 
Members of the academic community of universities are involved in research aimed at contributing to various aspects of sustainability.

The model recommends that universities should gradually try to move from disciplinary research (practiced in most universities) to interdisciplinary and transdisciplinary research. Having the previous stages of the model completed, which involves an understanding of the issue of sustainability for all stakeholders in a university, eases the process of integrating the research.

Human potential is the basic element in training and ensuring sustainability in the university environment. We have schematically shown (see Figure 4a) the components of human potential that contribute to the sleep of sustainability in the university environment.

The three steps of the integrating research, suggested by the model presented by Valanzquez are:

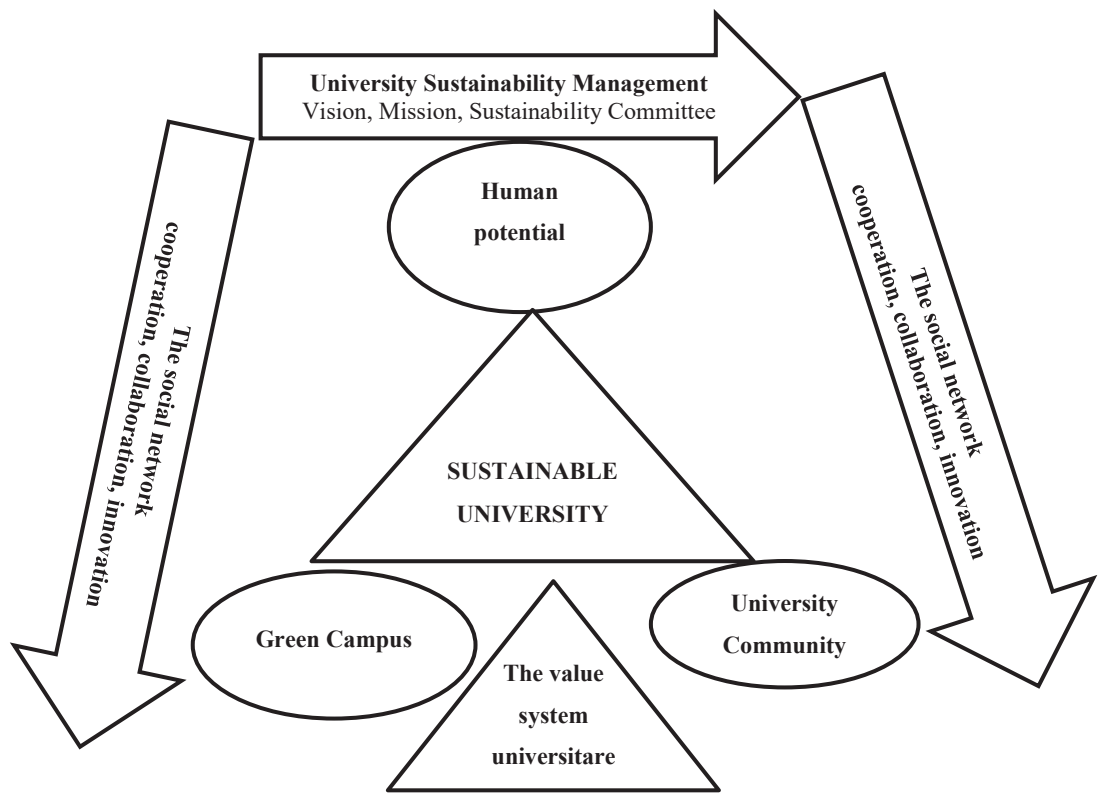

Figure 4. Own model of ensuring sustainability in higher education institutions in the Republic of Moldova

Source: adapted by Velanquez L., 2006 


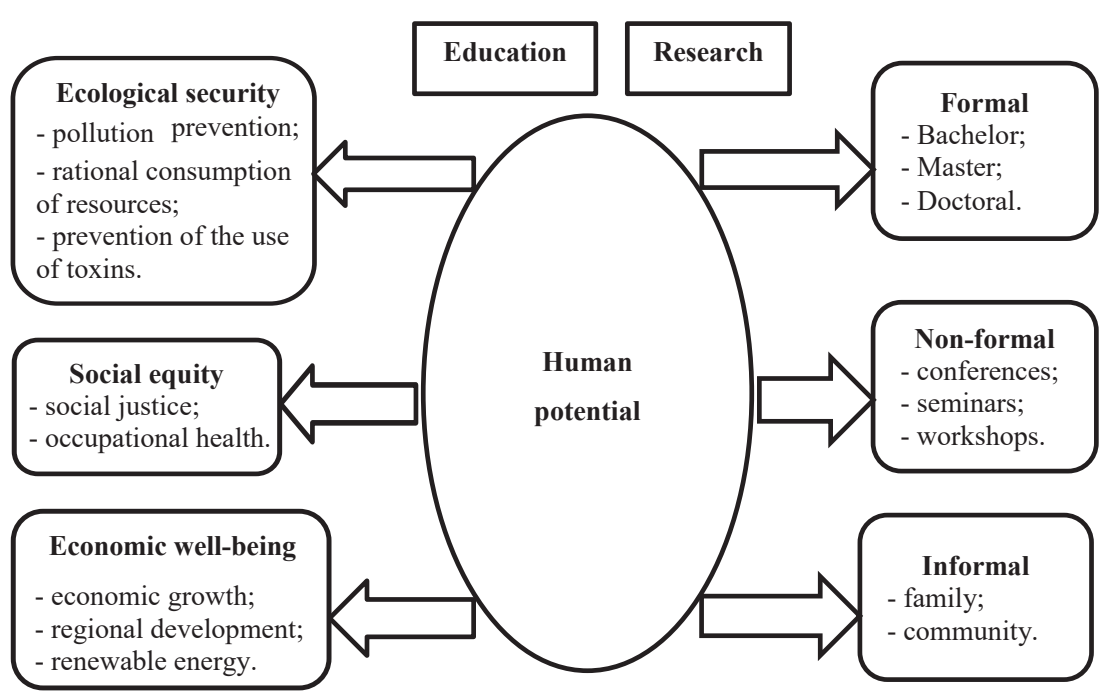

\section{Figure 4 a. Human potential ensuring sustainability in higher education institutions in the Republic of Moldova}

Source: adapted by Velanquez L., 2006

1. The disciplinary research focuses on a single discipline.

2 . The interdisciplinary research creates connections between disciplines and demonstrates systemic interrelationships among them.

3. The transdisciplinary research addresses the challenges faced by the people involved, and creates mutual learning connected with environmental issues, which are closely related to interdisciplinary systemic understanding [9].

The creation of the green campus ensures the efficiency of the process of ensuring sustainability in the university environment (see Figure $4 \mathrm{~b}$.).

The performance management. The performance management can be defined as a mechanism of improving the organizational performance by connecting and aligning with individual, team, and organizational goals and outcomes.

Critical success factors of performance management systems include their alignment with the strategic objectives of the organization, their structure and integration with other resource management functions.

De Cieri and Kramar suggest that performance management has three major goals: 


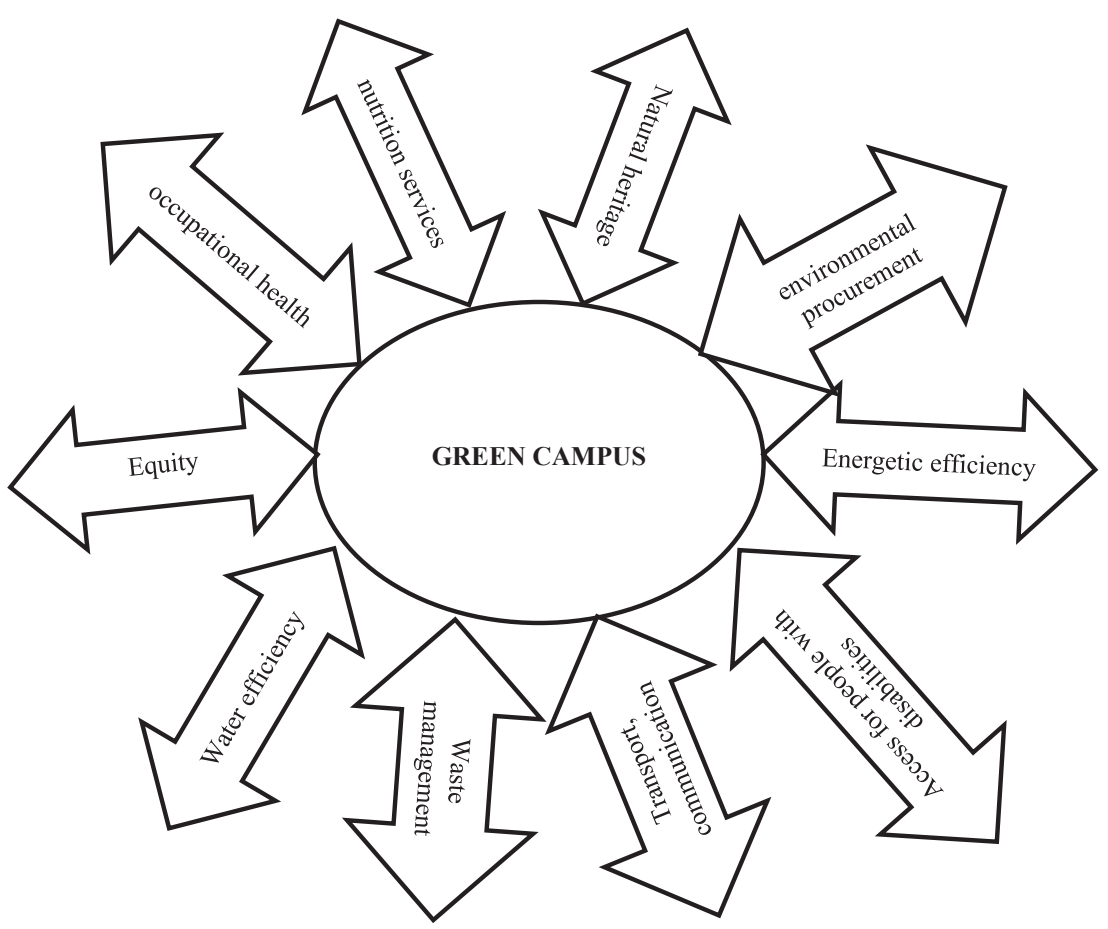

Figure 4 b. Greeen campus ensuring sustainability in higher education institutions in the Republic of Moldova

Source: adapted by Velanquez L., 2006

a. a strategic goal - a goal that comprises the emphasis on the way objectives should be connected;

b. a goal of development - with an emphasis on individuality;

c. an administrative goal - which includes making the right decisions [9].

The use of performance indicators as a way of managing and improving the performance in education is currently widespread within universities.

In order to have a successful implementation of the model, of the path to a sustainable university, a holistic vision should be adopted.

On the other hand, the model " $4 \mathrm{C}$ ", recommended by Jones, Selby and Sterling, suggests that the actions of the sustainable university should focus on: 
- curriculum;

- campus;

- institutional community;

- organizational culture [17, pp. 44-47].

In Figure 4 c., we showed the essence of the university community in the process of ensuring sustainability in the university environment

The three steps of the integrating research, suggested by the model presented by Valanzquez are:

1. The disciplinary research focuses on a single discipline.

2. The interdisciplinary research creates connections between disciplines and demonstrates systemic interrelationships among them.

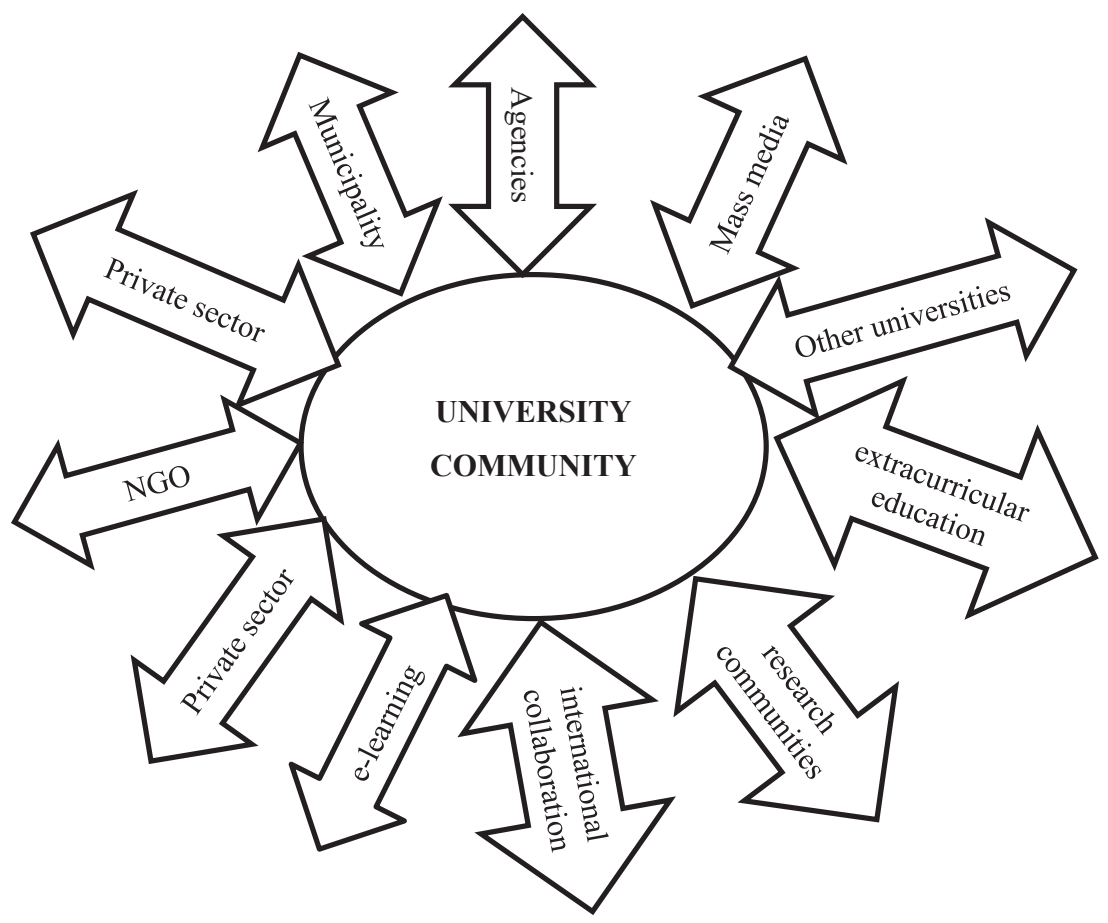

Figure 4 c. University community ensuring sustainability in higher education institutions in the Republic of Moldova 
3. The transdisciplinary research addresses the challenges faced by the people involved, and creates mutual learning connected with environmental issues, which are closely related to interdisciplinary systemic understanding [9].

In this context, "Studying programs include campus exploration, partnerships and community initiatives, and university culture from a sustainability perspective, while student and research encourage actions that can be campus-oriented, community-based and institutional cultural change".

Figure $4 \mathrm{~d}$., shows the contribution of the university value system in the process of ensuring sustainability in the university environment

Selby suggests that the university policy and action plans should embrace a holistic notion of sustainability that, over time, combines economic health, social justice and other humanitarian concerns [16].

Williams also emphasizes that "Education-for-sustainability is a holistic learning process, linking learning across environmental, social, economic and cultural dimensions so that students can acquire increasing understanding of the complexity of living within resource limits" [23, p. 22].

Williams states that "the culture of a particular university is the product of the universal history of the establishment of universities, the development

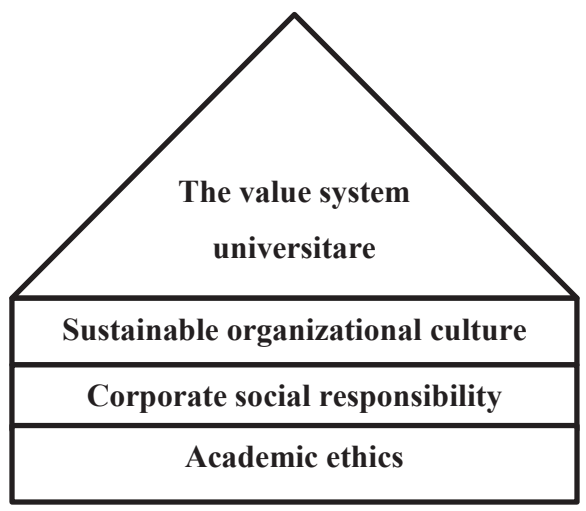

Figure $4 \mathrm{~d}$. The value system universitaire ensuring sustainability in higher education institutions in the Republic of Moldova of a particular university in place and time, the nature of the student population it engages with, research and teaching funding opportunities and, amongst other influences, the need for adherence to external statutes and expectations" [23, p. 216].

The researcher also argues that the current business culture of universities presents a barrier to the vital cross-sectoral dialogue that is needed to move from general awareness of a need to the realm of making effective changes for student learning of sustainability. 


\section{Successful experiences in achieving sustainability in the university environment}

If we were to present the experience of the countries in the efforts made to implement the activities related to sustainability, then we must reiterate the program "Take one step", which was developed by the Monash Institute for Achieving Sustainability at Monash University. This program is an online platform created for student involvement that is focused on stimulating movement and leadership actions to achieve sustainability activities within the university.

Interaction on the Internet involves competition between students, who are challenged to change their lives, guided by the principles of sustainability. At the same time, it is necessary to report on the progress made, to conduct surveys and preparatory materials for master studies. Students solve a number of problems, of which: reducing food waste, switching to responsible consumption, volunteer work for the benefit of local communities.

The interaction of participants in the program is due to the ability to share, evaluate and track someone else's progress.

The key success factors of the platform are the mobilization of students and company staff to implement the project and gamify the service. Take One Step is expected to progress, allowing students from different countries to interact, exchange ideas and solve common problems.

Monash University intends to update the platform website, adding another opportunity to the platform, such as the addition of instructional videos, collaboration tools and new gameplay elements. The new version of the site will be available to other universities and organizations [25].

Another successful experience in carrying out sustainability activities within universities in developed countries is related to "getting a doctorate degree in sustainability" based on the experience of Curtin University. In order to overcome the challenges and achieve the goals of sustainability at the global level, the community needs research focused on sustainability issues and identifying optimal ways to achieve them.

Carrying out doctoral studies in the field of sustainability at Curtin University creates conditions for the practical solution of the complex problems highlighted by sustainability.

Doctoral programme focused on sustainability issues at Curtin University is one of the first in this field. The first 15 graduate students of this program 
are already exchanging practical and professional experience in the field of sustainability with state and international organizations.

The $\mathrm{PhD}$ in Sustainability is supported by the world's top experts in sustainability, through active cooperation with governments, agencies, corporations and volunteer organizations. The main goal is to find concrete and optimal ways to integrate sustainability activities in practice and policy processes, identifying barriers to achieving sustainability goals [28].

Another great opportunity and experience about carrying out sustainability actions in higher education institutions is the "Training Development Program" at James Cook University. This program at James Cook University is based on sustainability activities in developing countries with tropical climates. Throughout the project activity, there is a close interaction between the university and the local organizations, the management team, civil society and local community representatives, which allows obtaining information about the situation on the ground, and about the conditions in which it is necessary to implement sustainability actions, and analyze, together with the stakeholders, the key scenario to achieve the objectives, using an integrated approach [29].

The internship or training development agenda at James Cook University provides students with the tools they need to eradicate poverty without disrupting the ecological balance in ecosystems.

The research carried out under the program aims to obtain data and results that contribute to the alignment of the decision-making process with the principles of sustainability. The university is committed to building long-term partnerships with other universities in the tropical regions of developing countries but also with civil society that shares its commitment to sustainability. The university is also trying to recruit graduates from the above countries, in order to develop local potential in the field of sustainability.

In addition to these beautiful experiences that many universities are already implementing, we also reiterate the beautiful experience at Monash University, which is the "Workshop for Sustainability-Oriented Students".

In order to achieve sustainability goals, it is essential to stimulate students' work in this area, and improve students' understanding of sustainability.

In October 2016, the Institute of Sustainability at Monash University became a platform for the Sustainability Student Forum. The purpose of the forum was 
to connect students with the university administration in order to discuss how student sustainability activities can become achievable within the university.

The main tasks of the forum were:

- uniting the people involved in the organization of student activities, related to sustainability on a website of Monash University;

- providing information on sustainability and its impact on the global environment;

- assessing how university students are currently contributing to sustainability-related activities;

- identifying areas of common interest and combining collaborative efforts;

- applying the brainstorming to stimulate student activity;

- increasing their interest in carrying out sustainability activities [30].

The participants appreciated the event and were inspired by the opportunity to find common interests with other students. Many had not heard of sustainability before the event or knew relatively little about these activities, so the forum was very helpful to them. Due to the forum activities, a wide range of potential projects was identified in the implementation of sustainability-related activities.

Another successful experience applied within world universities, namely the University of Sydney, is "Teaching in the Framework of Sustainability". In 2014, the University of Sydney developed a master degree programme labelled "Poverty Eradication and Profitability". The programme is closely associated with the first principle of sustainability, the topic of poverty and the study of the role of business in eliminating it.

The course takes a macroeconomic approach, analyzing business goals, along with the way sustainability objectives create a new meaning for business in a social context, as well as major scientific theories such as the concept of creating common value, etc.

The course was developed taking into account the issues discussed within the UN Leaders' Summit in New York. After completing the course, there were major changes in the students' value system and in their career ambitions. Based on the work done in creating and developing the course, the university has developed a similar interactive training course [31].

Another successful experience is represented by the "Curriculum Development in the Context of Sustainability" by Queen Victoria University of Wellington. 
An important mechanism by means of which universities can contribute to the achievement of sustainability activities is to educate students and help them develop the necessary skills and knowledge, but also to find solutions to achieve sustainability through the curriculum. Queen Victoria University of Wellington uses sustainability activities as an institutional framework that manages the university contribution to a sustainable future [27].

To this end, also through the prism of elucidating the sustainability activities, the content of over three thousand university courses was reviewed.

Queen Victoria University of Wellington has sought to identify the institutions and faculties that are leaders in introducing sustainability ideas into their courses, and also which of the 17 objectives are sufficient and underrepresented. A consultant was hired to systematize the processing of the obtained information by means of keywords, specifically formulated for each of the 17 objectives in the course description.

The obtained results facilitate an extensive discussion about the introduction of sustainability activities in the university activity, and in the university curricula. The project also provided data for a more detailed analysis of the possibilities for coordinating sustainability activities in the teaching community, promoting the establishment of links between experts in this field [27].

In addition to all these experiences applied within the universities in developed countries, we can mention "the development of a set of documents for the evaluation of sustainability activities" carried out by the University of Queensland.

Water is vital for survival, but despite this, every ninth inhabitant of the planet does not have access to clean drinking water, and every third inhabitant does not have access to modern sanitation services. The objectives of the international sustainability seek to ensure the accessibility and the sustainable management of water and sanitation for everybody.

In 2016, the University of Queensland published a series of three papers on achieving sustainability goals, with a special focus on goal no. 6 of sustainable development "clean water and sanitation services". The publications were produced by an interdisciplinary team of researchers working at the Institute for Global Change at the University of Queensland. The authors of the publications set out the following tasks:

- determining the working approach for sustainability; 
- identifying and expanding the links between sustainability objectives;

- conducting a detailed study of local community cooperation and capacity building [32].

The publications were widely disseminated outside the university with the intention to inform the decision-makers and the business about the sustainability objectives, but also the civil society representatives. The materials include requests from several organizations demanding guidance on how to implement sustainability objectives.

Another successful experience is represented by "A Network of Experts on Sustainability Issues", which has been implemented at the Technical University of Sydney. One of the key challenges for the universities working to implement sustainability goals is the difficulty of stimulating the interfaculty interaction [33].

In 2013, the conference "The Future of Development" was held within the Institute for Sustainability at the Technical University of Sydney. In the planning phase of the conference, communication was established with university staff, interested in issues of poverty and social justice.

Due to these activities, a network of experts in university development has been formed - a community of practitioners, focused on poverty eradication, development and social justice. The aim of the network is to promote cooperation, exchange of experience and collaborative research in various fields at the Technical University of Sydney [33].

The university network of experts organized two forums: one focused on "gender equality and sustainability goals", and the other prioritize on "energy and sustainability goals". These forums have created a favourable basis for the communication of research conducted by specialists from different faculties. The specificity of the selected sustainability objectives sets out specific directions for the discussions between the participants, while both forums emphasized the intersection of different sustainability objectives.

The efforts of the University of Worcester should also be highlighted, since the institution is ambitious to encourage a culture that appreciates sustainability and has a long-term commitment to acting in a sustainable and ecologically friendly environment.

The first sustainability policy was adopted in 2007. It is reviewed annually and persists to be a key value "promoting the principles of sustainability through teaching, research and knowledge exchange [...], promoting 
sustainable services and enterprises, and encouraging a culture that values sustainability in arts and culture to promote social enterprise in this field".

The sustainability strategy of the University of Worcester currently identifies 12 key policy areas comprising initiatives from techniques to behavior and designed to either mitigate negative impacts or provide positive programs for impact on the various stakeholder communities.

The University of Worcester has made progress in achieving this agenda by implementing a wide range of sustainability-related initiatives in these strategic areas, some of which are associated with the culture framework [34].

As a result, the university climbed from the 93rd place in People and Planet League in 2007 to the top 5 universities by 2016.

Specific examples of sustainability initiatives promoted at the University of Worcester include:

- investments in LED lighting courses;

- implementation of all recommendations within the framework of a water audit;

- changing toilets and installing low-flow showers on campuses [34].

Following the external validation and certification in May 2010, the University of Worcester became the best University in England, and won the EcoCampusPlatinum award for the entire campus.

Other accomplishments in the domain of sustainability have been observed at the University of Michigan, where researchers Marans et al., have reported successful operational and technical changes in their work, but have similarly failed to incorporate a culture of sustainability [35].

Since 2012, the University of Michigan has monitored students, staff and faculty members, in order to raise awareness of the university's efforts around key sustainability initiatives (climate action, waste reduction and creating healthy environments) [35].

Although not yet directly comparable, the achievements of the University of Worcester and the University of Michigan are becoming increasingly distinct.

\section{Conclusions}

In conclusion, we can reiterate that sustainability is the biggest challenge for the universities in the 21 st century. Since there are many definitions and interpretations of the concept, the strategies in the world universities that 
commence to strive for sustainability are different. Various universities in developed countries have already been involved in the process of integration towards sustainability.

It is not easy to achieve a sustainable university, but all the efforts made, related to the energy deposited, the resources allocated, and the time invested in many universities around the world, show considerable progress.

The implementation of the model suggested by us, should be done in order to form a sustainable university through incremental steps, as shown, and should be a process of continuous improvement of the ecological, economic and social environment.

The efforts of universities to become sustainable will inspire other organizations to engage in the process, and improve the effects achieved throughout society.

Universities have different approaches to the emergence of the sustainability process. Some universities have incorporated the sustainability into their visions and missions; others focus on sustainable education or research integration, while other universities have created environmental policies or campus strategies, but what is desirable, is an approach that includes all components of the given model.

\section{References:}

1. Alshuwaikhat, H.M. and Abubakar, I. (2008) An integrated approach to achieving campus sustainability: assessment of the current campus environmental management practices. In: Journal of Cleaner Production, vol. 16, no. 16, pp. 1777-1785.

2. Azizov, A. (2009) Obrazovanie v interesah ustoychivogo razvitiya [cited 25.01.2021]. Available at: http://www.unesco.org/new/fileadmin/MULTIMEDIA/ FIELD/Tashkent/pdf/part1 correct.pdf

3. Cole, L. (2003) Assessing sustainability on Canadian university campuses: development of a campus sustainability assessment framework". In: Master of Arts in Environment and Management Master, Royal Roads University, Victoria.

4.Consiliul UE „Higher education sustainability initiative”, (2018) [cited 25.01.2021]. Available at: https://sustainabledevelopment.un.org/sdinaction/hesi

5. Constantinescu, A. (2013) Coordonate ale managementului dezvoltării durabile din perspectiva culturii organizaționale. In: Management intercultural, vol. XV, no. 1, 27, pp. 20-34 [citat 25.01.2021]. Available at: http://seaopenresearch.eu/Journals/articles/MI_27_3.pdf

6. Cortese, A.D. (2003) The critical role of higher education in creating a sustainable future. In: Planning for Higher Education, vol. 31, no. 3, pp. 15-22.

7. Davidova, T., Barkalov, S. (2019) Content and evaluation of innovative componentsw of human potential in the ratings of universities. In: International 
Scientific Conference, vol. VI, May 24th-25th, pp. 117-132 [cited 25.01.2021]. Disponibil: https://www.researchgate.net/publication/337334685 CONTENT AND_EVALUATION_OF_INNOVATIVE_COMPONENTS_OF ${ }_{\text {HUMAN }}{ }_{-}^{-}$ POTENTIAL IN THE RAT̄INGS OF UNIV̄ERSITIES

8. Erpenbeck, J., Rosenstiel, L. ' (2003) Handbuch Kompetenzmessung. Erkennen, verstehen und bewerten von Kompetenzen in der betrieblichen, pädagogischen und sychologischen Praxis. Stuttgart: Schäffer-Poeschel.

9. Grecu, V., Nagore, I. (2014) The sustainable university - a model for the sustainable organization. In: Management of Sustainable Development Sibiu, Romania, vol. 6, no. 2, December 2014 [cited 25.01.2021]. Disponibil: https://www.researchgate.net/publication/276424502_The_Sustainable_ University___A_Model_for_the_Sustainable_Organization

10. Lindroos, P. (2007) From National to Global Cooperation - the Baltic Sea Region as an Example, in Kaivola, T. Available at: http://julkaisut.turkuamk.fi/ isbn9789522161499.pdf

11. Manualul UNESCO „Educație pentru obiectivele dezvoltării durabile”, (2014), [cited 12.01.2021]. Available at: http://dezvoltaredurabila.gov.ro/web/ wp-content/uploads/2017/12/manual-UNESCO.pdf

12. Report of the World Commission on Environment and Development: Our Common (2020), [cited 25.01.2021]. Available at: https://sustainabledevelopment.un.org/ content/documents/5987our-common-future.pdf

13. Rhoen, D., Mansilla, V., Chun, M. and Klein, J.T. (2006) Interdisciplinary Education at Liberal Arts Institutions, Teagle Foundation White Paper, New York NY

14. Rosendaal, H. (2018) Strategic issues in university management, [cited 25.01.2021]. Available at: https://www.researchgate.net/publication/254859218 Strategic_Issues_in_University_Management

15. Schumacher, F. (2011) The world improvement plans of Fritz Schumacher. In: Cambridge journal of economics, March, 2011, pp. 1-17 [cited 25.01.2021]. Available at: ttps://www.researchgate.net/publication/227464557_The_world improvement_plans_of_Fritz_Schumacher/link/55478b420cf2e 2031b36f1 fe/ download

16. Selby, K.E. (1997) Creating value with the intangible asset monitor [cited 20.01.2021]. Available at: https://www.sveiby.com/files/pdf/the-intangible-assets-monitor.pdf

17. Sterling, S. (2004) An Analysis of the Development of Sustainability Education Internationally: Evolution, Interpretation and Transformative Potential. In: J. Blewitt \& C. Cullingford (Eds.), The Sustainability Curriculum: The Challenge for Higher Education, pp. 43-62. London: Earthscan Publications Ltd.

18. Strategia UE privind Dezvoltarea Durabilă, (2010), [cited 12.01.2021]. Available at: http://publications.europa.eu/resource/cellar/8d8026dc-d7d7-4d048896-e13ef636ae6b.0014.02/DOC 5

19. Tilbury, D. (2004) Environmental Education for Sustainability: A force for change in higher education. In P. B Corcoran. \& A. E. J. Wals (Eds.), Higher Education and the Challenge of Sustainability: Problematics, promise and practice, pp. 97-112. Dordrecht: Kluwer Academic Press. 
20. Turban, E., Sharda, R., and al. (2010) Business Intelligence: A Managerial Approach, 2nd edition, Canada, Pearson Education Canada.

21. Urbaniec, M. (2018) Ksztaltowanie kompetencji studentów zgodnie z zasadami odpowiedzialnej edukacjimened żerskiej. Horyzonty Wychowania17, 167-76.

22. Velazquez, L., Munguia, N., and al. (2006) Sustainable university: what can be the matter? In: Journal of Cleaner Production, vol. 14, no. 9/11, pp. 810-819.

23. Williams, P.M. (2008) University Leadership for Sustainability A Dendritic Framework for Enable Connection and Collaboration, $\mathrm{PhD}$ Thesis at Victoria University of Wellington, [cited 20.01.2021]. Available at: http://www.futuresteps.co.nz/PhD_University_Leadership_for_Sustainability.pdf

24. UI GreenMetric World University Rankings (2020) Wageningen University and Research, Netherlands - The World's Most Sustainable University [cited 25.01.2021]. Available at: http://greenmetric.ui.ac.id/wp-content/uploads/2015/07/ press-release-UI-GreenMetric-World-University-Rankings-2020.pdf

25. The program take on step. Available at: www.takeonestep.com.au

26. The University of Queensland. Available at: gci.uq.edu.au/sustainable-water

27. The Victoria University. Available at: www.victoria.ac.nz/about/governance/sustainability-office

28. The Curtin University. Available at: www.sustainability.curtin.edu.au/

29. The study at James Cook. Available at: https://www.jcu.edu.au/?utm source $=$ google\&utm_medium $=c$ cpc\&utm_campaign $=$ branding\&utm_term $=$ james cook university\&utm_content $=429854 \overline{67} 8101 \&$ gclid $=$ CjwKCAiAgc-ABhA7EiwAjev-j9tMOa6v3dSFprQcSLpM5MIotf6wre3uuHFJMavtAYC-Pua5-41SNxoC9IQQAvD_BwE

30. The Monach University. Available at: https://www.monash.edu/

31. The University of Sydney. Available at: http://www.sydney.edu.au/newsopinion/news/2017/04/06/on-my-mind.html

32. The University of Queensland, Australia, Available at: https://www.uq.edu.au/

33. The University of Technology Sydney. Available at: https://utscollege.edu.au/ pathway?utm_campaign=domestic-campaign-2020\&utm_medium $=$ cpc\&utm source $=$ search $\& u$ tm_content $=$ pathway-lp\&utm_term $=\&$ gclid $=$ CjwKCAiAgc-ABhA7EiwAjev-jxJnJīz4nYYpAzkQrO8EVDjMZZxe5LkHJ9UfeebuOMG4xUpFGEtxr-RoCkrkQAvD_BwE

34. The University of Worcester. Available at: https://www.worcester.ac.uk/ campaigns/apply-to-study?gclid=CjwKCAiAgc-ABhA7EiwAjev-j7d51tgYzRSQ8axPGAgsHUSkxYRXr12t8feXbfqibzrSgrn4GXQZdhoCM8gQAvD_BwE

35. The Western Michigan University. Available at: https://wmich.edu 